Surgery for

Congenital

Heart Disease

\title{
Baboons undergoing orthotopic concordant cardiac xenotransplantation surviving more than 300 days: Effect of immunosuppressive regimen
}

\author{
Miki Asano, MD, ${ }^{a}$ Steven R. Gundry, MD, ${ }^{a}$ Hironori Izutani, MD, ${ }^{a}$ Sandra Nehlsen Cannarella, PhD, \\ Omar Fagoaga, $\mathrm{PhD},{ }^{\mathrm{b}}$ and Leonard L. Bailey, $\mathrm{MD}^{\mathrm{a}}$
}

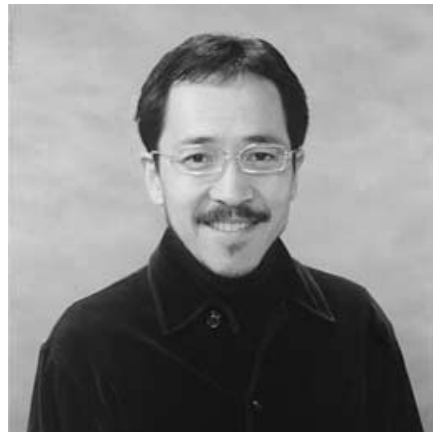

Dr Asano

Objective: We reviewed long-term survival among hosts in 3 consecutive series of a rhesus monkey-baboon orthotopic cardiac xenotransplantation model with reference to host immune response, including the effectiveness in preventing rejection and limiting toxicity concerning infection, to evaluate specific immunosuppressive regimens for long-term outcomes.

Methods: Six juvenile baboons surviving more than 300 days after transplantation were reviewed. Regimen A consisted of splenectomy, FK506, methotrexate, and antilymphocyte globulin. Regimen B consisted of pretransplantation and chronic maintenance with cyclosporine A (INN: ciclosporin), methotrexate, and antithymocyte globulin. Regimen $\mathrm{C}$ was the same as regimen B plus pretransplantation total lymphoid irradiation and intraoperative donor bone marrow cell infusion. Rejections were detected by means of echocardiography.

Results: Long-term survivors in 3 groups were followed for a range of 332 to 515 days (mean, 436 days). Rejection frequency in regimens $\mathrm{A}, \mathrm{B}$, and $\mathrm{C}$ was $0.35,0.58$, and 0.18 per month, and rescue therapy days were $23(4.8 \%), 123(9.5 \%)$, and 20 (2.4\%), respectively $(P<.0001)$. Infection frequency was $0.58,0.56$, and 0.19 per month, and therapy days were 192 (38.2\%), 164 (12.6\%), and $7(0.9 \%)$, respectively $(P<.0001)$. Concerning the host immune response, interleukin $2-$ activated $\mathrm{T}$ cells of all groups during rejection-free periods showed lower numbers compared with those of control animals $(P<.0005)$, and regimen $\mathrm{C}$ was the lowest among 3 groups $(P<.01)$. The production of xenoantibody was sufficiently attenuated in all groups.

Conclusion: Regimen $\mathrm{C}$ leads to long-term survival with fewer rejection and infection episodes by means of suppression of the interleukin 2 pathway and xenoantibody production.

Address for reprints: Steven R. Gundry, MD, Department of Surgery, Loma Linda University Medical School and Medical Center, 11175 Campus St, Suite 21121, Loma Linda, CA 92354 (E-mail: Steven.Gundry@tenethealth.com).

J Thorac Cardiovasc Surg 2003;125:60-70

Copyright $(9) 2003$ by The American Association for Thoracic Surgery

$0022-5223 / 2003 \$ 30.00+0$

doi: $10.1067 / \mathrm{mtc} .2003 .89$

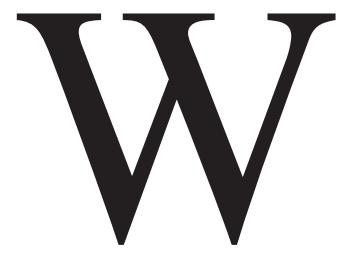

e have continued to study orthotopic concordant and discordant cardiac xenotransplantation for a solution to the severe shortage of allogeneic donor supply, especially in the field of cardiac transplantation in infants and children. ${ }^{1-10}$ Instead of exploring transgenic donors, simplified host immunosuppressive protocols that could be used in clinical cardiac transplantation have been adapted to our xenotransplantation research. We have focused on survival studies of orthotopically xenografted juvenile baboon recipients 
TABLE 1. Immunosuppressive regimens of the 3 groups (regimens A, B and C)

\begin{tabular}{|c|c|c|c|c|c|c|c|c|c|}
\hline & \multicolumn{2}{|c|}{ Pretransplantation } & \multirow{2}{*}{$\begin{array}{c}\begin{array}{c}\text { Pretransplantation } \\
\text { and }\end{array} \\
\text { peritransplantation } \\
\text { Adjunct }\end{array}$} & \multicolumn{2}{|c|}{ During transplantation } & \multicolumn{4}{|c|}{ Posttransplantation } \\
\hline & Splenectomy & TLI & & DHI & DBMI & FK & CsA & MTX & $\begin{array}{c}\text { Rescue } \\
\text { MP }\end{array}$ \\
\hline A & () & & $A L G$ & (2) & & (2) & & () & (0) \\
\hline B & & & CsA,MTX ATG & & & & () & (0) & (0) \\
\hline C & & (0) & CsA,MTX ATG & & (0) & & () & (2) & (2) \\
\hline
\end{tabular}

DHI, Donor heart irradiation (100 cGy); DBMI, donor bone marrow infusion $\left(3 \times 10^{8} / \mathrm{kg}\right)$; FK, FK506 $\left(18 \mathrm{mg} \cdot \mathrm{kg}^{-1} \cdot \mathrm{d}^{-1}\right)$; CsA, cyclosporine A (pretreatment, $15 \mathrm{mg} . \mathrm{kg} . \mathrm{d}$; maintenance target dose, $200 \sim 300 \mathrm{ng} / \mathrm{ml}) ; A L G$, antilymphocyte globulin, $\left(4 \mathrm{mg} \cdot \mathrm{kg}^{-1} \cdot \mathrm{d}^{-1}\right)$; $A T G$, antithymocyte globulin $\left(15 \mathrm{mg} \cdot \mathrm{kg}^{-1} \cdot \mathrm{d}^{-1}\right) ; M^{2} X$, methotrexate (pretreatment, $1 \mathrm{mg} \cdot \mathrm{kg} \cdot \mathrm{d}$; maintenance dose, $0.1 \sim 5 \mathrm{mg} /$ day); $M P$, methylepredonisone (4-day course rescue therapy, $250 \mathrm{mg} / \mathrm{day}$ ).

with hearts from rhesus monkey donors and successfully obtained long-term survival outcomes in 3 consecutive series, ${ }^{2,7,10}$ using somewhat different immunosuppressive strategies in each. We reviewed findings related to those hosts who survived more than 300 days after transplantation as to the effectiveness in preventing rejection and limiting toxicity with regard to infection and the host immune response to assess which combination of specific immunosuppressive regimens leads to the best long-term outcome.

\section{Materials and Methods}

Donors, Recipients, and Immunosuppressive Regimens

Eighteen juvenile baboons (body weight, 2.5-4.8 kg; age, 7-19 months) from the same colonies received orthotopic cardiac transplantation from $\mathrm{ABH}$ blood-type compatible and mixed lymphocyte culture-matched rhesus monkeys. Animals were divided into 3 consecutive series on the basis of the immunosuppressive strategy. Seven baboons received immunosuppressive regimen A, 6 received regimen $\mathrm{B}$, and 5 received regimen $\mathrm{C}$ (see below). Six recipients ( 1 of regimen $\mathrm{A}, 3$ of regimen $\mathrm{B}$, and 2 of regimen $\mathrm{C}$ ) survived more than 300 days after surgical intervention and were reviewed. Regimen A consisted of preoperative splenectomy, intraoperative donor heart irradiation (100 cGy), administration of antibaboon lymphocyte sheep globulin $\left(4 \mathrm{mg} \times \mathrm{kg}^{-1} \times \mathrm{d}^{-1}\right)$ from day -3 to day +5 , FK506 (18 $\left.\mathrm{mg} \times \mathrm{kg}^{-1} \times \mathrm{d}^{-1}\right)$, and methotrexate (0.1-5 mg twice weekly, dose adjusted to keep white blood cell counts $>3000$ ) administered as maintenance immunosuppressants. In regimen B 8 days of pretransplantation and peritransplantation treatment with cyclosporine (INN: ciclosporin; $15 \mathrm{mg} \times$ $\left.\mathrm{kg}^{-1} \times \mathrm{d}^{-1}\right)$, methotrexate $(1 \mathrm{mg} / \mathrm{kg})$, and antithymocyte globulin $\left(15 \mathrm{mg} \times \mathrm{kg}^{-1} \times \mathrm{d}^{-1}\right)$ was given. Maintenance therapy consisted of cyclosporine $\left(15 \mathrm{mg} \times \mathrm{kg}^{-1} \times \mathrm{d}^{-1}\right)$ and methotrexate $(0.5-5$ $\mathrm{mg}$ twice weekly). In regimen $\mathrm{C}$ nonlethal total lymphoid irradiation (TLI) was used in a dose of $80 \mathrm{cGy}$ from a cobalt 60 source twice weekly for 5 weeks before transplantation plus infusion of $3 \times 10^{8} / \mathrm{kg}$ bone marrow cells collected from the donor immediately after completion of surgical procedures. From 2 weeks before transplantation, cyclosporine $\left(15 \mathrm{mg} \times \mathrm{kg}^{-1} \times \mathrm{d}^{-1}\right)$ and methotrexate $(1 \mathrm{mg} / \mathrm{kg}$ twice weekly) were administered. Antithymocyte globulin $\left(15 \mathrm{mg} \times \mathrm{kg}^{-1} \times \mathrm{d}^{-1}\right)$ was administered from day -3 to day +10 . Maintenance therapy was the same as that of regimen B.
Rescue therapy consisted of a 4-day course of methylprednisolone (250 mg/d, Table 1).

\section{Operative Procedures}

The transplantation procedure was the same as we have described elsewhere. ${ }^{11,12}$ In brief, xenografts were harvested from rhesus monkeys and preserved with cold Roe crystalloid cardioplegia and immersed in cold saline solution $\left(4^{\circ} \mathrm{C}\right)$. In regimen $\mathrm{A}$ grafts were irradiated with $100 \mathrm{cGy}$ before implantation. In regimen $\mathrm{C}$ both femurs and iliac crest marrow of the donor rhesus monkeys were harvested for bone marrow transfusion. All recipients received 125 $\mathrm{mg}$ of methylprednisolone, antibiotic, and $3 \mathrm{mg} / \mathrm{kg}$ heparin just before the operation. A median sternotomy was used for both explantation and implantation of grafts. Grafts were implanted orthotopically by using circulatory arrest. All animals were separated from cardiopulmonary bypass without inotropic support. Animals were extubated within 2 to 3 hours after the operation. All recipients recovered smoothly, and no technical failure occurred.

\section{Evaluation, Diagnosis, and Definitions}

The effects of immunosuppressive regimens in long-term surviving animals were evaluated on the basis of the following: effectiveness in preventing rejection and limiting toxicity with regard to infection, cardiac function, drug dosage, physical development and host immune response elucidated by examination of lymphocyte subsets, and presence of xenoantibody. Rejection episodes were evaluated by means of both rejection frequency and total rescue therapy days. Diagnosis of rejection was mainly based on echocardiography, with findings of increasing graft wall thickness, new pericardial effusion, and deterioration of wall motion and also based on general symptoms (ie, lethargy, anorexia, and tachycardia). However, no rejection episode was diagnosed solely on the basis of general symptoms. Echocardiography has been used clinically for primary rejection surveillance after infant heart transplantation at Loma Linda University Medical Center, ${ }^{13}$ and this could be greatly valuable in these juvenile animal models with limited venous access instead of using sequential myocardial biopsies. Biopsy was used once in 2 regimen A animals, respectively, to attempt to differentiate cellular versus humoral rejection. Completion of the rejection episode was defined as that time when rescue therapy was completed and cardiac findings were improved. The rejection period was defined as the period from 6 days before 
TABLE 2. Profile of all animals among the 3 groups

\begin{tabular}{|c|c|c|c|c|c|c|}
\hline & Animal no. & $\begin{array}{l}\text { Survival } \\
\text { (d) }\end{array}$ & Time course of rejections (postoperative day) & $\begin{array}{l}\text { Rejection } \\
\text { (n) }\end{array}$ & $\begin{array}{l}\text { Infection } \\
\text { (n) }\end{array}$ & Cause of death \\
\hline \multirow[t]{7}{*}{ Regimen A } & $1(\# 1)$ & 502 & $55,379,392,414,420,483$ & 6 & 10 & CMV pneumonia \\
\hline & 2 & 234 & $60,94,188,212,219$ & 5 & 3 & Toxoplasmosis \\
\hline & 3 & 123 & $49,82,90$ & 3 & 5 & CMV pneumonia \\
\hline & 4 & 96 & 42 & 1 & 4 & Renal failure \\
\hline & 5 & 74 & $16,42,74$ & 3 & 5 & Pulmonary embolism \\
\hline & 6 & 43 & & 0 & 2 & CMV pneumonia \\
\hline & 7 & 35 & 32 & 1 & 1 & Klebsiella pneumonia \\
\hline \multirow[t]{6}{*}{ Regimen B } & $1(\# 2)$ & 515 & $11,109,395,411,441,485$ & 6 & 9 & PTCAD \\
\hline & $2(\# 3)$ & 413 & $9,25,79,138,203,216,236,249,264,287,294$ & 11 & 7 & Herpes virus infection \\
\hline & $3(\# 4)$ & 371 & $8,37,141,159,177,198,269$ & 8 & 4 & Papova virus infection \\
\hline & 4 & 223 & $8,17,28,36,47,62,84,94,105,119,127,138,171,222$ & 14 & 3 & Acute rejection \\
\hline & 5 & 59 & 7,55 & 2 & 1 & Acute rejection \\
\hline & 6 & 50 & 44,50 & 2 & 1 & Acute rejection \\
\hline \multirow[t]{5}{*}{ Regimen C } & $1(\# 5)$ & 486 & $20,107,292$ & 3 & 2 & Alive \\
\hline & $2(\# 6)$ & 332 & 135,284 & 2 & 3 & Alive \\
\hline & 3 & 88 & 67,85 & 2 & 0 & Acute rejection \\
\hline & 4 & 35 & 30 & 1 & 0 & Acute rejection \\
\hline & 5 & 10 & & 0 & 0 & Gastroenterocolitis \\
\hline
\end{tabular}

No important differences were observed among the 3 groups in the survival period. Regimen $C$ animals showed the lowest value both in rejection frequency $(0.38 \pm 0.37 / \mathrm{mo})$ and infection frequency $(0.08 \pm 0.12 / \mathrm{mo})$. The numbers parenthesized mean serial numbers of long-term surviving animals. CMV, Cytomegalovirus; PTCAD, posttransplant coronary artery disease.

the diagnosis until the day of diagnosis because echocardiography was used once a week routinely. The rejection-free period was defined as the time more than 2 weeks after transplantation and at least 2 weeks from any documented rejection episode. If infection occurred during the rejection-free period, it was subtracted from the rejection-free period.

Infection episodes were evaluated on the basis of both infection frequency and total intravenous antibiotic therapy days. Diagnosis of infection was based on the following: temperature increase to greater than $39^{\circ} \mathrm{C}$, white blood cell count of greater than 12,000 , results of blood culture, chest radiography, and clinical symptoms (ie, diarrhea and rhinorrhea). The infection period was defined as the duration from the day of diagnosis until the completion of intravenous antibiotic, ganciclovir therapy, or both coupled with improvement in findings and symptoms. The diagnosis of cytomegalovirus disease was made if the virus was detected in culture from blood, sputum, or both (cytomegalovirus viremia, pneumonia, or both).

Cardiac function was evaluated on the basis of left ventricular ejection fraction. The weekly dosage of methotrexate was used as the measure of drug dosage. The evaluation of physical development depended on the body weight expressed as $z$ values obtained by transforming the observed weight in kilograms to the number of SDs from the mean normal value by the weight obtained from untreated baboons in our laboratory.

Peripheral blood lymphocytes and serum were collected once or twice a week. Lymphocytes were analyzed for cell-surface antigens $\left(\mathrm{CD} 2^{+}, \mathrm{CD} 20^{+}, \mathrm{CD} 2^{+} \mathrm{CD} 4^{+}, \mathrm{CD} 2^{+} \mathrm{CD} 8^{+}\right.$, and $\mathrm{CD} 25^{+} \mathrm{CD} 2^{+}$) by means of 2-color flow cytometry with murine antihuman monoclonal antibodies. Xenoantibody titers against rhesus monkey red blood cells were measured in the standard hemagglutination assay.
Data from recipient baboons before any pretransplantation treatment were considered control data. Concerning the immunologic profiles of control animals, no difference existed among the 3 groups. According to the definition of rejection-free period and rejection period, the number of rejection-free period versus rejection period measurement points from which data were obtained for evaluation of each group was 31 versus 14 in regimen A, 41 versus 25 in regimen $B$, and 58 versus 12 in regimen $C$, respectively. The number of control values was 20 .

This research was approved by the institutional animal care committee of Loma Linda University Medical Center. All animals received human care in compliance with the Guide for the Care and Use of Laboratory Animals prepared by the Institute of Laboratory Animal Resources and published by the National Institutes of Health (publication no. 86-23, revised 1985).

\section{Statistical Analysis}

Unless otherwise stated, continuous variables are expressed as means \pm SD. Nominal variables were compared among the 3 groups by using the $\chi^{2}$ test for independence. Continuous variables were compared by using analysis of variance. An unpaired Student $t$ test was used to compare continuous variables between the rejection-free period and the rejection period within each group. One-way analysis of variance and post hoc testing (Scheffe method) were used to compare the control group and the 3 groups in the rejection-free period and to compare among the 3 groups in the rejection period, as well as among the 3 groups when including all animals. Actuarial survival curves obtained with the KaplanMeier method were compared by using log-rank analysis. All statistical analyses were performed with StatView 5.0 for Macintosh (SAS Institute Inc). 


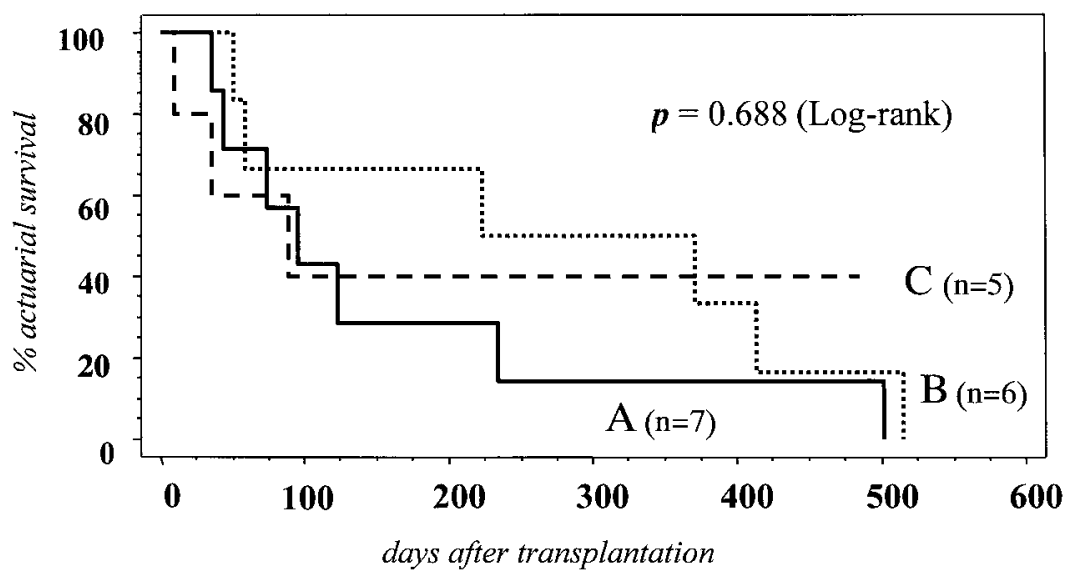

Figure 1. Actuarial survival of the 3 groups. Actuarial survival at 300 days after transplantation was $14.3 \%$ in regimen $A$ animals, $50 \%$ in regimen $B$ animals, and $40 \%$ in regimen $C$ animals.

\section{Results}

\section{Profile of All Animals in the 3 Groups}

Table 2 delineates the profile of all animals in the 3 groups. The survival period of each group was $158 \pm 165$ days in regimen A, $272 \pm 193$ days in regimen B, and $190 \pm 209$ days in regimen $\mathrm{C}$, respectively. No statistical differences were observed among the 3 groups. Actuarial survival of the 3 groups also indicated no remarkable difference by means of log-rank test ( $P=.688$, Figure 1). Concerning rejection episodes, numbers were $0.59 \pm 0.40$ per month of rejection frequency in regimen $\mathrm{A}, 0.98 \pm 0.53$ per month in regimen $\mathrm{B}$, and $0.38 \pm 0.37$ per month in regimen $\mathrm{C}$, respectively. There was an important difference only between regimens $\mathrm{B}$ and $\mathrm{C}(P=.0395)$. Initial rejection after transplantation was observed on day $42.8 \pm 15.9$ in regimen $\mathrm{A}$, day $14.5 \pm 14.5$ in regimen $\mathrm{B}$, and day $63.0 \pm 52.0$ in regimen $\mathrm{C}$, respectively. A statistical difference was obtained between regimens $\mathrm{B}$ and $\mathrm{C}(P=.02)$. As regards infection episodes, numbers were $1.10 \pm 0.55$ per month of infection frequency in regimen $\mathrm{A}, 0.48 \pm 0.10$ per month in regimen $\mathrm{B}$, and $0.08 \pm 0.12$ per month in regimen $\mathrm{C}$, respectively. Between regimens $\mathrm{A}$ and $\mathrm{C}$, a remarkable difference $(P=.0002)$ was observed. Regimen $\mathrm{C}$ animals showed the lowest value in infection frequency, as well as the lowest value in rejection frequency. Importantly, infection caused $71 \%$ of the deaths in regimen $\mathrm{A}, 33 \%$ in regimen $\mathrm{B}$, and none in regimen $\mathrm{C}$. In regimen $\mathrm{C}$ animals 3 had grade 2 graft-versus-host disease and died of acute rejection 88 days after transplantation. Animal 5 died of gastroenterocolitis caused by radiation injury. Moreover, long-term survivors had completely similar tendencies in results concerning rejection and infection observed among the 3 groups including all animals.

\section{Profile of Long-term Survivors}

Animal 1 in regimen A died from cytomegalovirus pneumonia and bacterial sepsis. Autopsy revealed severe post- transplantation coronary arteriopathy without acute rejection. Animal 2 in regimen $B$ died of posttransplantation coronary arteriopathy. Another 2 animals in regimen $\mathrm{B}$ died of viral infection, and no significant transplantation-related coronary artery disease was identified (Table 2).

\section{Rejections and Infections in Long-term Survivors}

The total number of rejection episodes was 6 in regimen A animals in 17 months, 25 (6 in animal 2, 11 in animal 3, and 8 in animal 4) in regimen B animals in 43 months, and 5 (3 in animal 5 and 2 in animal 6) in regimen $C$ animals in 27 months, respectively. Therefore rejection frequency was 0.35 per month in regimen A animals, 0.58 per month in regimen $\mathrm{B}$ animals, and 0.18 per month in regimen $\mathrm{C}$ animals, respectively. The number of rescue therapy days was $23(4.8 \%)$ of 502 days in regimen A animals, 123 $(9.5 \%)$ of 1299 days in regimen B animals, and $20(2.4 \%)$ of 818 days in regimen $C$ animals, respectively. Animal 3 in regimen $\mathrm{B}$ received TLI ( 80 cGy twice weekly; total, 800 cGy) for intractable and recurrent rejection from day 390. Regimen C recipients were had lower values in terms of rejection frequency and also statistically lower values in terms of rescue therapy days $(P<.0001$, Table 3$)$.

The total number of infection episodes was 10 in regimen A animals, 21 (9 for animal 2, 7 for animal 3, and 8 for animal 4) in regimen $\mathrm{B}$ animals, and 5 (3 for animal 5 and 2 for animal 6) in regimen $\mathrm{C}$ animals, respectively. Therefore infection frequency was 0.58 per month in regimen $\mathrm{A}$ animals, 0.56 per month in regimen $B$ animals, and 0.19 per month in regimen $\mathrm{C}$ animals, respectively. The number of intravenous antibiotic therapy days was 192 (38.2\%) in regimen A animals, 164 (12.6\%) in regimen B animals, and $7(0.9 \%)$ in regimen $\mathrm{C}$ animals, respectively. Animal 1 received ganciclovir therapy for cytomegalovirus from day 309 to day 353 and had Klebsiella pneumonia on day 334. Animals 3 and 4 also received ganciclovir therapy from day 
TABLE 3. Rejection episodes among the 3 groups

\begin{tabular}{lcccc}
\hline & Regimen A & Regimen B & Regimen C & $P$ value \\
\hline $\begin{array}{l}\text { Rejection } \\
\text { frequency }\end{array}$ & 0.35 & 0.58 & 0.18 & \\
Therapy days & 23 & 123 & 20 & \\
& $(4.8 \%)$ & $(9.5 \%)$ & $(2.4 \%)$ & $<.0001$ \\
\hline
\end{tabular}

The total number of rejection episodes was 6 during 17 months in regimen A, 25 during 43 months in regimen $B$, and 5 during 27 months in regimen $C$. Regimen $C$ recipients were lower in frequency and also lower in rescue therapy days, with clinical significance $(P<.0001)$.

Rejection frequency, total rejection episodes/total follow-up months; \% in parenthesis, total rescue therapy days/total follow-up days.

270 and day 353, respectively. Animal 2 had pneumonia from day 412. On the contrary, regimen $\mathrm{C}$ animals showed no severe infections requiring sequential intravenous antibiotic therapy and experienced less infection. Thus the immunosuppressive modality used in regimen $\mathrm{C}$ recipients yields fewer infection episodes $(P<.0001$, Table 4$)$.

\section{Weekly Dosage of Methotrexate in Long-term \\ Survivors}

The dosage of methotrexate (in milligrams per week) was $3.1 \pm 2.2$ in regimen A animals, $5.1 \pm 1.6$ in regimen B animals, and $4.3 \pm 1.2$ in regimen $\mathrm{C}$ animals, respectively. There were differences among the 3 groups $(P<.0001)$, with the regimen A dose being lower.

\section{Change of Ejection Fraction in Long-term Survivors} Ejection fraction of the 3 groups in rejection-free period versus rejection period was $77.7 \% \pm 5.2 \%$ versus $72.2 \% \pm$ $7.5 \%$ in regimen $A$ animals, $78.4 \% \pm 4.3 \%$ versus $73.5 \% \pm$ $5.0 \%$ in regimen $\mathrm{B}$ animals, and $81.1 \% \pm 7.2 \%$ versus $75.3 \% \pm 8.5 \%$ in regimen $\mathrm{C}$ animals, respectively. The control value was $83.4 \% \pm 5.9 \%$. Although there were no important differences among the 3 groups, regimen $\mathrm{A}$ and $\mathrm{B}$ animals in rejection-free periods showed lower values compared with control values $(P=.0344$ and .0187 , respectively; Figure 2).

\section{Change of Body Weight}

All but one (animal 3) long-term surviving animals in regimen $\mathrm{B}$ increased in body weight naturally, and their $z$ values decreased between 0.5 and -2 up to 400 days after transplantation. Animal 3 experienced chronic malnutrition and frequent episodes of severe diarrhea induced by immunosuppression and required tube feeding from day 90 to day 160 , with whole-blood transfusions required several times (Figure 3).

\section{Flow Cytometric CD2 ${ }^{+}$Cell Profile}

The absolute number of $\mathrm{CD}^{+} \mathrm{T}$ cells (1000 per microliter) in the rejection-free period versus the rejection period was
TABLE 4. Infection episodes among the 3 groups

\begin{tabular}{lcccc}
\hline & Regimen A & Regimen B & Regimen C & $\boldsymbol{P}$ value \\
\hline $\begin{array}{l}\text { Infection } \\
\text { frequency }\end{array}$ & 0.58 & 0.56 & 0.19 & \\
Therapy days & $\begin{array}{c}192 \\
(38.2 \%)\end{array}$ & $\begin{array}{c}164 \\
(12.6 \%)\end{array}$ & $\begin{array}{c}7 \\
(0.9 \%)\end{array}$ & $<.0001$ \\
\hline
\end{tabular}

The total number of infection episodes was 10 in regimen $A, 21$ in regimen $B$, and 5 in regimen $C$, respectively. Therapy days means the number of intravenous antibiotic therapy days. Regimen $\mathrm{C}$ recipients experienced lower frequency and also less therapy days, with clinical significance. Infection frequency, Total infection episodes/total follow-up months; \% in parenthesis, therapy days/total follow-up days.

$2.87 \pm 1.19$ versus $4.17 \pm 1.17$ in regimen $\mathrm{A}$ animals, $1.08 \pm 0.42$ versus $1.57 \pm 0.56$ in regimen $B$ animals, and $0.83 \pm 0.52$ versus $2.03 \pm 0.70$ in regimen $C$ animals, respectively. The control value was $2.87 \pm 1.22 . \mathrm{CD}^{+} \mathrm{T}$ cells increased during rejection periods in all groups. During rejection-free periods, the absolute number of $\mathrm{CD} 2^{+}$cells among regimen $\mathrm{B}$ and $\mathrm{C}$ animals were lower than those of control animals $(P<.0001)$. During rejection periods, $\mathrm{CD} 2{ }^{+}$cell counts were lower for regimen $\mathrm{B}$ and $\mathrm{C}$ animals than for regimen A animals $(P<.0001)$. Administration of FK506 resulted in an increase of the CD2 ${ }^{+}$T-cell population, negating the difference between control and regimen $\mathrm{A}$ animals $(P>.9999))^{3,4}$

\section{Flow Cytometric CD20 ${ }^{+}$B-cell Profile}

The absolute number of $\mathrm{CD} 20^{+} \mathrm{B}$ cells (1000 per microliter) in the rejection-free period versus the rejection period was $0.21 \pm 0.19$ versus $0.28 \pm 0.14$ in regimen $\mathrm{A}$ animals, $0.22 \pm 0.07$ versus $0.40 \pm 0.36$ in regimen $B$ animals, and $0.28 \pm 0.20$ versus $0.47 \pm 0.20$ in regimen $C$ animals, respectively. The control value was $0.51 \pm 0.23$. In rejection-free periods, $\mathrm{CD} 20^{+}$decreased in all groups compared with that seen in the control animals $(P<.0001)$, but no important differences existed among the 3 groups $(P=$ .9973 for regimens A vs B, $P=.3371$ for regimens A vs C, and $P=.3807$ for regimens $\mathrm{B}$ vs $\mathrm{C}$ ).

\section{Flow Cytometric CD2 ${ }^{+} \mathrm{CD}^{+}{ }^{+}$Helper T-cell Profile}

The absolute number of $\mathrm{CD} 2{ }^{+} \mathrm{CD} 4^{+}$helper $\mathrm{T}$ cells $(1000$ per microliter) in the rejection-free period versus the rejection period was $0.89 \pm 0.50$ versus $1.06 \pm 0.35$ in regimen A animals, $0.59 \pm 0.20$ versus $0.81 \pm 0.30$ in regimen $\mathrm{B}$ animals, and $0.28 \pm 0.15$ versus $0.70 \pm 0.29$ in regimen $C$ animals, respectively. The control value was $1.54 \pm 0.66$. During rejection-free periods, $\mathrm{CD} 2{ }^{+} \mathrm{CD} 4^{+}$helper $\mathrm{T}$ cells decreased in all groups compared with control values $(P<$ $.0001)$, and differences existed among the 3 groups $(P=$ .0071 for regimens A vs B, $P<.0001$ for regimens A vs $\mathrm{C}$, and $P=.0008$ for regimens $\mathrm{B}$ vs $\mathrm{C}$ ). $\mathrm{CD} 2{ }^{+} \mathrm{CD} 4^{+}$cell 


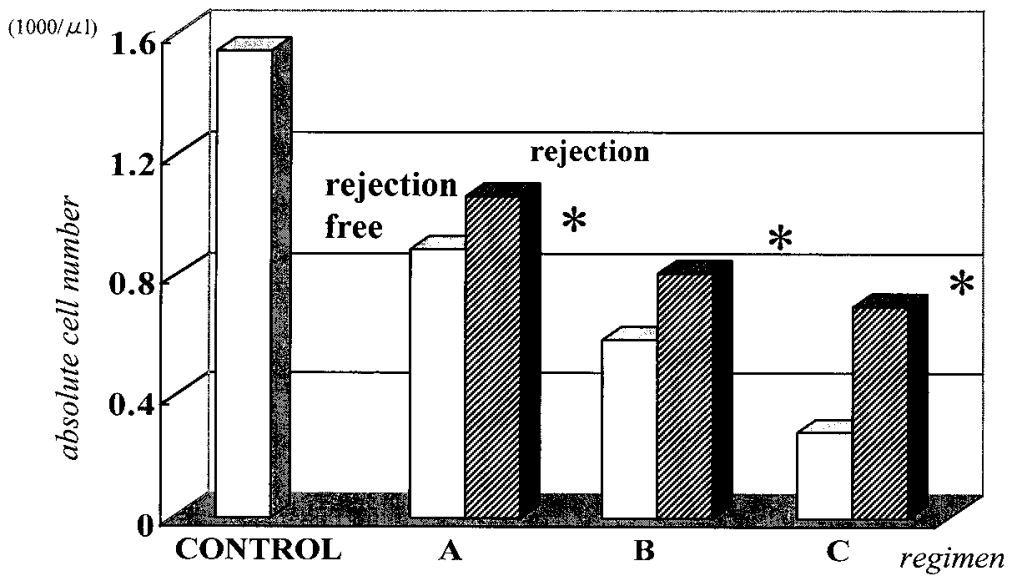

Figure 2. Change in ejection fraction. Although there were no important differences among the 3 groups, regimen $A$ and $B$ animals showed lower values compared with those of control animals $(P=.0344$ and .0187 , respectively). ${ }^{*}$ Existence of difference between periods $(P=.0061$ for regimen $A$ animals, $P<.0001$ for regimen $B$ animals, and $P=.0167$ for regimen C animals).

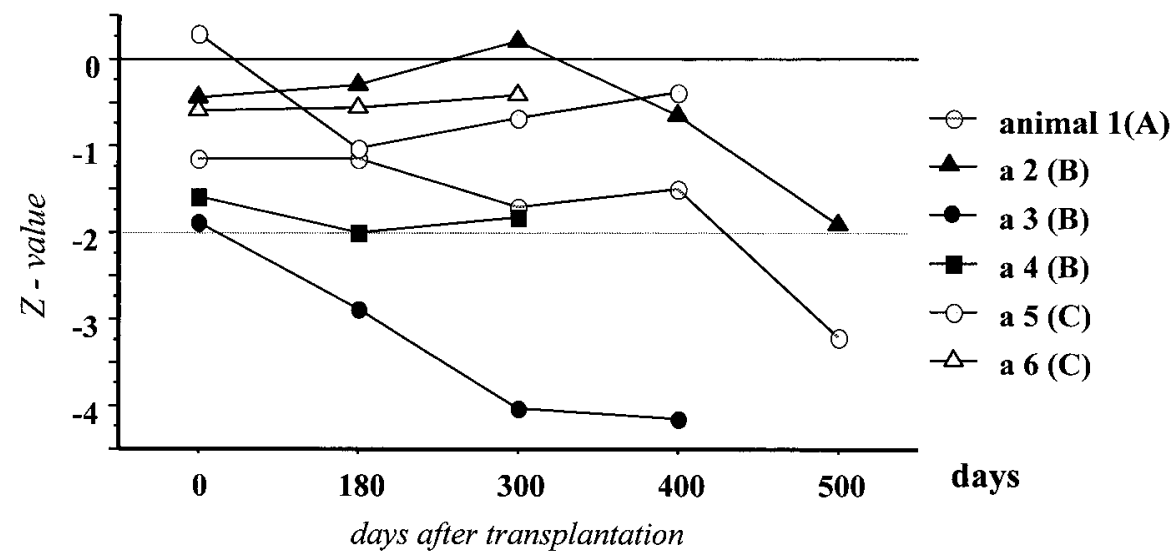

Figure 3. Change in body weight. All but one of the study animals increased in body weight naturally. The normal values for $94 \%$ of the animals lies between -2 and 2 ( $z$ value $=$ [Observed data - Mean of normal group]/SD).

counts were the lowest for regimen $\mathrm{C}$ animals during rejection-free periods (Figure 4, $A$ ).

\section{Flow Cytometric CD2 ${ }^{+} \mathrm{CD8}^{+}$Cytotoxic/Suppressor \\ T-cell Profile}

The number of $\mathrm{CD} 2^{+} \mathrm{CD}^{+}$cytotoxic/suppressor $\mathrm{T}$ cells (1000 per microliter) in the rejection-free period versus the rejection period was $1.69 \pm 0.81$ versus $2.68 \pm 0.71$ in regimen $\mathrm{A}$ animals, $0.48 \pm 0.23$ versus $0.73 \pm 0.31$ in regimen $\mathrm{B}$ animals, and $0.49 \pm 0.37$ versus $1.15 \pm 0.72$ in regimen $\mathrm{C}$ animals, respectively. The control value was $1.31 \pm 0.62$. During rejection-free periods, the number of $\mathrm{CD} 2^{+} \mathrm{CD} 8^{+}$cells decreased in regimen $\mathrm{B}$ and $\mathrm{C}$ animals compared with control values and were also lower than those observed in regimen A animals $(P<.0001)$.
Flow Cytometric $\mathrm{CD}^{+}{ }^{+} \mathrm{CD2}^{+}$Interleukin 2-activated T-Cell Profile

The number of $\mathrm{CD} 25^{+} \mathrm{CD} 2{ }^{+}$interleukin 2 (IL-2)-activated $\mathrm{T}$ cells (1000 per microliter) in the rejection-free period versus the rejection period was $0.12 \pm 0.06$ versus $0.15 \pm$ 0.05 in regimen $\mathrm{A}$ animals, $0.14 \pm 0.05$ versus $0.17 \pm 0.05$ in regimen $\mathrm{B}$ animals, and $0.03 \pm 0.01$ versus $0.08 \pm 0.03$ in regimen $\mathrm{C}$ animals, respectively. The control value was $0.27 \pm 0.28$. During rejection-free periods, all 3 groups showed lower numbers compared with control values $(P<$ .0001 for regimens $\mathrm{A}$ and $\mathrm{C}, P=.0002$ for regimen $\mathrm{B}$ ), and regimen $\mathrm{C}$ was the lowest among the 3 groups. Regimen $\mathrm{C}$ animals were more suppressed than the other groups with regard to IL-2-activated T cells (Figure 4, B). 

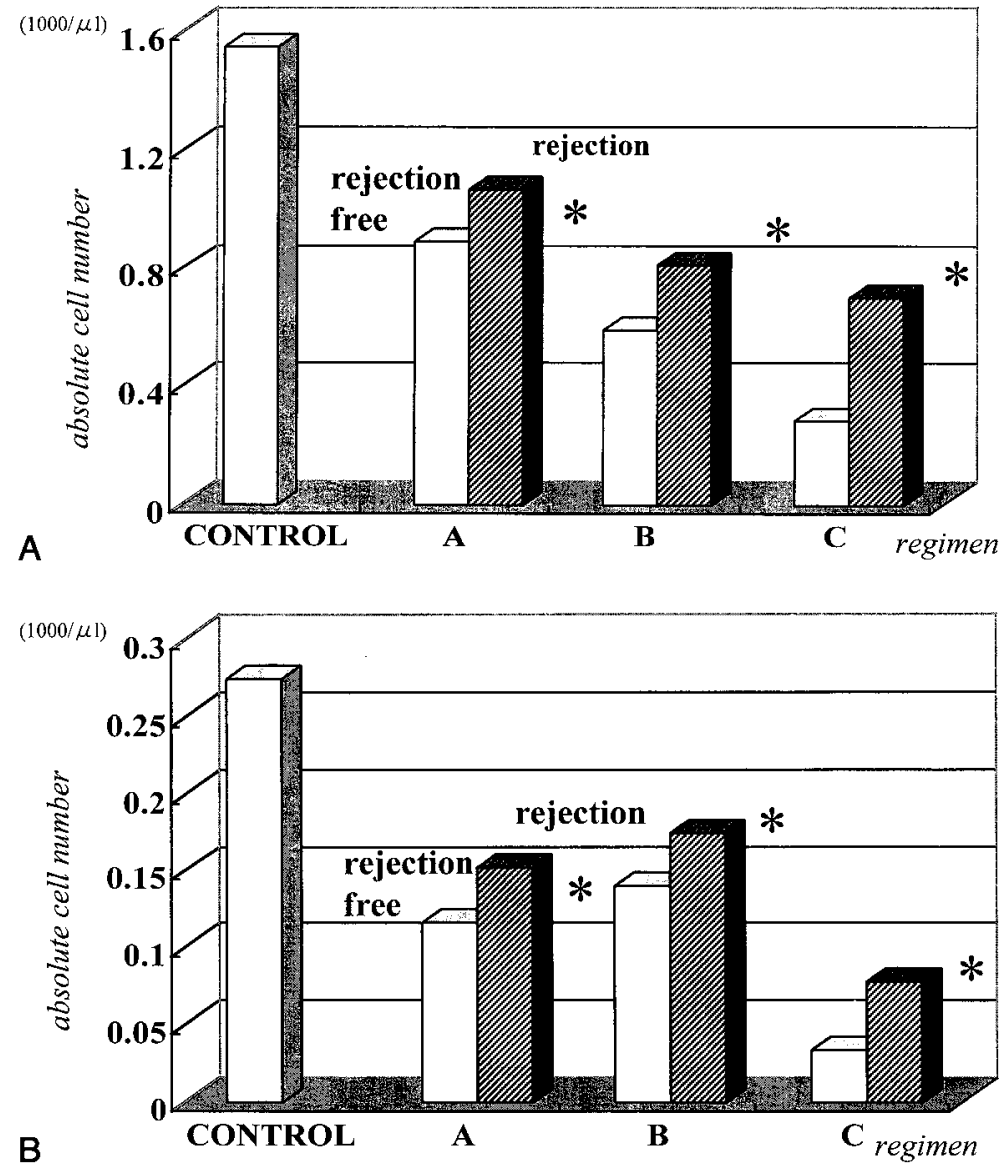

Figure 4. A, $\mathrm{CD2}^{+} \mathrm{CD}^{+} \mathrm{T}$ cells decreased in all groups compared with control values $(P<.0001)$, and differences existed among the 3 groups $(P=.0071$ between regimens $A$ and $B$ and $P=.0008$ between regimens $B$ and $C) .{ }^{*}=$ .2523 in regimen $A, P=.0006$ in regimen $B$, and $P<.0001$ in regimen $C$ between both periods. $B, C D 25^{+} C D 2^{+}$ IL-2-activated T-cell profile. During rejection-free periods, all groups showed lower numbers compared with control values $(P<.0001$ in regimens $A$ and $C$ and $P=.0002$ in regimen $B)$. Regimen $C$ was the lowest among the 3 groups in rejection-free periods $(P=.0088$ between regimens $A$ and $C, P<.0001$ between regimens $B$ and $C)$. ${ }^{*} P=.0587$ for regimen $A, P=.0073$ for regimen $B$, and $P<.0001$ for regimen $C$ between both periods.

\section{Xenoantibody in Long-term Survivors}

Serum xenoantibody to donor rhesus monkey red blood cells was not detected during the first 3 months after transplantation in regimen $\mathrm{B}$ animals, and titers detected thereafter were low, ranging from 1:1 to 1:8. The examination of explanted graft by means of immunohistochemistry elucidated no deposits of $\operatorname{IgG}$ and $\operatorname{IgM}$ in animals 2 and 3; this was not used in animal 4 . No xenoantibody was detected in regimen $\mathrm{C}$ animals, even after 1 year of transplantation. Xenoantibody to donor lymphocyte was measured in regimen A animals, but no significant titers were found, and these were equivalent to antibaboon lymphocyte antibody titers. In addition, immunofluorescent study of the explanted heart of animal 1 showed no deposits of IgG or IgM on the endothelium of the coronary arteries and the aorta. ${ }^{6}$

\section{Discussion}

These 3 consecutive series of a rhesus monkey-baboon orthotopic cardiac xenotransplantation model were conducted during a nearly 10 -year period at our laboratory to refine and develop a simple and effective immunosuppressive regimen that would be feasible for clinical use. During this time, we have tried to develop a regimen that would produce donor-specific unresponsiveness or tolerance without the need for continuous immunosuppression. This was obviously not achieved. However, comparison of the longterm survivors indicate an obvious advantage in using regimen $\mathrm{C}$ for xenotransplantation.

\section{Rejection Episodes and Infection Episodes}

In regimen A animals, although rejection episodes were sufficiently controlled with FK506 and a remarkably low 
dose of methotrexate, refractory infection episodes required intravenous drug therapy for up to $38 \%$ of total survival days and resulted in frequent sepsis. From the immune profile, it appears that this regimen dose not result in aggressive immunosuppression when compared with the other 2 regimens. A synergy between FK506 and methotrexate is presumably responsible for the control of rejection. High susceptibility to infection was possibly induced by splenectomy, which does have the adverse effect of increasing late infectious mortality. ${ }^{14}$ Although splenectomy conferred long-term graft survival when using reduced-dose FK506, ${ }^{15}$ it reduces circulating IgM and complement levels, ${ }^{16,17}$ and alveolar macrophage bactericidal function is depressed after splenectomy. ${ }^{18}$ Another explanation is that FK506 predisposes the recipient to more serious infection and resultant death. ${ }^{19}$

In regimen B the greater rejection frequency and greater number of rescue therapy days was possibly induced by a weaker suppression of the IL-2 T-cell activation pathway than in the other 2 groups of animals (as described in the "Host Immune Response" section). The higher dose of methotrexate also contributed to increased susceptibility to infection, perhaps through the reduction of antibody-forming cells both after antigenic and mitogenic stimulation. ${ }^{20}$

The lowest number of rejection episodes and days of rejection treatment and also the lowest number of infection episodes and days of antibiotic intravenous therapy were observed among the long-term survivors of regimen C. We intended to produce mixed lymphohematopoietic chimerism among recipients in regimen C. However, animal 5 showed $0.5 \%$ mixed chimerism in groin lymph node analysis by means of flow cytometry 8 months after transplantation, and no chimerism was detected in animal $6 .{ }^{10}$ Although TLI in conjunction with cytolytic therapy and bone marrow transfusion might render recipients a high incidence of donorspecific tolerance through the establishment of a chimeric status, we could not detect sufficient mixed chimerism in this study. The construction of xenogenic chimerism is undoubtedly difficult, but more specific reagents that can distinguish donor hematopoietic elements from those of recipients might be needed to say for certain that mixed chimerism did not exist in these animals. ${ }^{21}$ Indeed, we could not detect any evidence of chimerism in peripheral blood lymphocytes or organ specimens of even the animals that had graft-versus-host disease. Conversely, in an allograft model a small fraction of donor lymphohematopoietic elements, even transiently with flow cytometry, might be sufficient to designate donor-specific tolerance. Therefore the lessened rejection and infection episodes in regimen $\mathrm{C}$ animals was assumed to be the result of a stable and wellsuppressed T-cell function. The maintenance of all classes of serum immunoglobulin in the normal range by TLI plays an important role for protecting against infections. ${ }^{22}$ How- ever, care must be taken for radiation gastroenterocolitis and graft-versus-host disease in this regimen.

\section{Ejection Fraction}

Ejection fraction was maintained without any inotropic drugs, diuretic drugs, or both in regimen $\mathrm{C}$ recipients. Severe rejections, frequent rejections, or both preclude a complete recovery of cardiac function, even after completion of rescue therapy. Indeed, persistent paradoxical septal wall motion, arrhythmia, and hypertrophic changes were observed in several cases of non-regimen $\mathrm{C}$ animals. Extensive replacement-type myocardial fibrosis reflecting some prior myocardial injury was confirmed pathologically, even without evidence of active rejection in animal 3. Animal 1 was administered digitalis and diuretics for control of a chronic pericardial effusion from day 400 onward, and animal 2 was prescribed diuretics and prednisone $(5 \mathrm{mg} 3$ times week) from day 456 onward for chronic pericardial effusion and peripheral edema.

\section{Physical Development}

All but one of the long-term surviving animals gained weight, normally indicating that cardiac function was maintained sufficiently for physical development in almost all animals. However, after day 400, animals 1 and 2, who gained weight normally until approximately 5.5 to $6.2 \mathrm{~kg}$, showed cessation of body weight gain and eventually decreased in weight. This plateau level was almost the same as the normal body weight of adult rhesus monkeys. It is conceivable that hearts might be genetically programmed for each species, and this could regulate the growth development and maximum size of xenografts. ${ }^{8}$ However, it is more likely that the plateau was reached simply because of diminishing cardiac function caused by repeated rejection episodes.

\section{Host Immune Response}

Our previous studies have suggested that both cellular and humoral factors are responsible for the rhesus monkeybaboon xenograft rejection, ${ }^{3,4,7}$ and therefore it is obvious that sufficient suppression of both factors should be a requisite for good long-term outcome. In general, all 3 regimens suppressed $\mathrm{T}$-cell function on the basis of modulated cell numbers. $\mathrm{CD} 2{ }^{+} \mathrm{CD} 4^{+}$helper $\mathrm{T}$ cells and $\mathrm{CD} 25^{+} \mathrm{CD} 2^{+}$ IL-2-activated $\mathrm{T}$ cells were sufficiently decreased. In the 3 regimens, FK506 and cyclosporine, as maintenance immunosuppressants, inhibit IL-2 mRNA accumulation and interfere with an early step in T-cell activation by decreasing IL-2 secretion, resulting in a decreased number of IL-2activated $\mathrm{T}$ cells $\mathrm{s}^{23}$ and thus affecting T-cell proliferation. In spite of using FK506, which is 10 to 100 times more potent than cyclosporine in its ability to inhibit transcription of the IL2 gene in regimen A animals, the lowest number of 
IL-2-activated $\mathrm{T}$ cells was observed in regimen $\mathrm{C}$ animals. In regimen $\mathrm{C}$ animals the presence of the lowest number of helper T cells and IL-2-activated T cells supports the prevailing effect of TLI in reducing the activation of T cells by IL-2 because it is known that helper T cells decrease persistently after TLI coupled with a concomitant slow increase in suppressor $\mathrm{T}$ cells, resulting in an inversion of CD4/CD8 ratio. Although this phenomenon remains incompletely defined, in part the effect might be due to physiologic differences in the radiosensitivity of $\mathrm{T}$ cell. ${ }^{24,25}$ This predominance of suppressor $\mathrm{T}$ cells inhibits the generation of cytotoxic $\mathrm{T}$ cells and decreases the production of cytokines from helper T cells, including IL-2, and this reduction is a mechanism by which TLI might induce tolerance. The host and graft interaction was suppressed or tolerated because of a prevalence of suppressor $\mathrm{T}$ cells and their ability to attenuate helper-inducer $\mathrm{T}$ cells, cytotoxic $\mathrm{T}$ cells, and $\mathrm{B}$ cell expansion, activation, and maturation. ${ }^{24}$ This host immune response profile continues to be observed over 300 days after the procedure and suggests that TLI results in a very long-lasting immunosuppressive effect. Of course, this effect might also be a synergistic effect of TLI and cyclosporine in xenotransplantation by inhibiting xenoantibody and cell-mediated response, especially suppressing $\mathrm{CD} 4^{+}$ helper $\mathrm{T}$ cells, thus resulting in long-term acceptance of rhesus monkey cardiac xenografts. ${ }^{22,26,27}$

Regarding the $\mathrm{CD} 20^{+} \mathrm{B}$-cell profile and the sufficiently attenuated xenoantibody production, all 3 regimens were effective in suppression of B-cell function. FK506 has biphasic effects on B-cell function; namely, when used at a low dose, negative proliferation signaling through $\operatorname{IgM}$ is inhibited, and an acceleration of cell division is observed. Conversely, when administered at high doses, positive proliferation signaling through $\operatorname{IgD}$ is suppressed, and it also suppresses the production of tumor necrosis factor, which acts as an autocrine growth factor for B cells. ${ }^{28,29}$ Therefore splenectomy as a supplement to FK506 is useful to maintain the steady suppression of B-cell numbers and function. However, considering the increased risk of susceptibility to infection, another specific suppression with anti-B-cell antibody substituted for splenectomy should be considered. In regimen $\mathrm{B}$ animals, beginning 6 months after transplantation, xenoantibody was detected but showed no relation to rejection. It might be because the prevention of antidonor antibody formation in the initial posttransplantation period allowed for prolonged concordant xenograft survival. ${ }^{30}$ In regimen $\mathrm{C}$ animals not surviving in the long term, very low levels of xenoantibody titers ranging from 1:1 to 1:2 were show, as well as and a lack of deposition of immunoglobulin in endothelium, as determined by means of immunofluorescent study. However, one of these animal had acute and chronic coronary arteriopathy in explanted grafts. Humoral rejection is possibly one of the causes of graft coronary arteriopathy in xenotransplantation. Differentiation between humoral and cellular rejection is not readily possible without the biopsy material in every rejection episode. Therefore we might address the limitation of the model in that the diagnosis of rejection episodes are not completely specific.

\section{Conclusions}

We conclude that regimen $\mathrm{C}$ leads to long-term survival with fewer rejection and infection episodes. This was accomplished by suppression of T-cell numbers and function, especially by inhibiting the proliferation through the IL-2 pathway, and by suppression of xenoantibody production. Although obvious immune tolerance and chimerism were not established, TLI resulted in a host immune response that was readily controlled by a clinically applicable regimen of maintenance immunosuppression that did not increase the risk of infection.

At the time of this report, animal 5 in regimen $\mathrm{C}$ is still alive on day 680, without signs of rejection and infection. Her immune profile dose not differ from that described in this article.

We greatly appreciate the technical support of Geoffery Visbal.

\section{References}

1. Alonso de Begona J, Gundry SR, Kawauchi M, et al. Assessment of baboon lymphocyte subsets and activity in cardiac xenobridging to allotransplantation. Transplant Proc. 1992;24:453-4.

2. Kawauchi M, Gundry SR, Alonso de Begona J, et al. Prolonged survival of orthotopically transplanted heart xenograft in infant baboons. J Thorac Cardiovasc Surg. 1993;106:779-86.

3. Fukushima N, Fagoaga O, Kawauchi M, et al. Lymphocyte subset markers as predictors of survival after concordant cardiac xenotransplantation. Transplant Proc. 1994;26:1212-3.

4. Kawauchi M, Fukushima N, Gundry SR, Alonso de Begona J, Nehlsen-Cannarella S, Bailey LL. Lymphocyte subset monitoring can detect xenoheart rejection in primates. Transplant Proc. 1994;26: 1067-9.

5. Fukushima N, Bouchart F, Gundry SR, et al. The role of anti-pig antibody in pig-to-baboon cardiac xenotransplant rejection. Transplantation. 1994;57:923-8.

6. Fukushima N, Kawauchi M, Bouchart F, et al. Graft atherosclerosis in concordant cardiac transplantation. Transplant Proc. 1994;26:105960.

7. Matsumiya G, Gundry SR, Nehlsen-Cannarella S, et al. Successful long-term concordant xenografts in primates: alteration of the immunoresponse with Mexotrexate. Transplant Proc. 1996;28:751-3.

8. Matsumiya G, Gundry SR, Fukushima N, Kawauchi M, Zuppan CW, Bailey LL. Pediatric cardiac xenograft growth in a rhesus monkey-tobaboon transplantation model. Xenotransplantation. 1996;3:76-80.

9. Xu H, Gundry SR, Hancock WW, et al. Prolonged discordant xenograft survival and delayed xenograft rejection in a pig-to-baboon orthotopic cardiac xenograft model. J Thorac Cardiovasc Surg. 1998; 115:1342-9

10. Izutani H, Gundry SR, Asano M, Fagoaga O, Zuppan CW, Bailey LL. Probable failure of chimerism induction in orthotopically transplanted monkey hearts in baboons. Transplant Proc. 2000;32:1049-51.

11. Bailey LL, Jang J, Johnson W, Jolley WB. Orthotopic cardiac xenografting in the newborn goat. J Thorac Cardiovasc Surg. 1985;89: 242-7.

12. Bailey LL, Conception W, Shattuck H, Huang L. Method of heart transplantation for treatment of hypoplastic left heart syndrome. J Thorac Cardiovasc Surg. 1986;92:1-5. 
13. Boucek MM, Mathis CM, Boucek RJ, et al. Prospective evaluation of echocardiography for primary rejection surveillance after infant heart transplantation: comparison with endomyocardial biopsy. J Heart Lung Transplant. 1994;13:66-73.

14. Samimi F, Irish WD, Eghtesad B, Demetris AJ, Startzl TE, Fung JJ. Role of splenectomy in human liver transplantation under modern-day immunosuppression. Dig Dis Sci. 1998;43:1931-7.

15. Kashu Y, Abe Y, Miyauchi K, et al. The effect of combination splenectomy and low-dose FK506 therapy on graft survival after liver allograft transplantation in rats. Transplantation. 1996;61:1522-5.

16. Ge Y, Gao H, Kong XT. Immunoglobulins and complement in splenectomized and autoretrotransplanted subjects. Ann Med. 1989;21: 265-7.

17. Fujita F, Matai K, Kohno S, Itsubo K. Impact of splenectomy on circulating immunoglobulin levels and the development of postoperative infection following totalgastrectomy for gastric cancer. $\mathrm{Br} \mathrm{J}$ Surg. 1996;83:1776-8.

18. Herbert JC, O'Reilly M. Granulocyte-macrophage colony timulating factor (GM-CSF) enhances pulmonary defense against pneumococcal infections after splenectomy. J Trauma. 1996;41:663-6.

19. Neuhaus P, Blumhardt G, Bechstein WO, et al. Comparison of FK506- and cyclosporine-based immunosuppression in primary orthotopic liver transplantation. Transplantation. 1995;59:31-40.

20. Pizarro TT, Malinowska K, Kovacs FJ, Clancy J Jr, Robinson JA, Piccinini LA. Diminished cytotoxic gene expression in rat cardiac transplantation with low-dose cyclosporine/methotrexate therapy. Transplantation. 1994;58:223-31.

21. Ko DSC, Bartholomew A, Poncelet AJ, et al. Demonstration of multilineage chimerism in a nonhuman primate concordant xenograft model. Xenotransplantation. 1998;5:298-304.

22. Roslin MS, Tranbaugh RE, Panza A, et al. One-year monkey heart xenograft survival in cyclosporine-treated baboons. Transplantation. 1992;54:949-55.

23. Tocchi MJ, Matkovich DA, Collier KA, et al. The immunosuppressant FK506 selectively inhibits expression of early T cell activation genes. J Immunol. 1989;143:718-26.

24. Ross HJ, Gullestad L, Pak J, Slauson S, Valantine HA, Hunt SA. Methotrexate or total lymphoid radiation for treatment of persistent or recurrent allograft cellular rejection: a comparative study. J Heart Lung Transplant. 1997;16:179-89.

25. Halperin EC, Bollinger RR. The role of irradiation in solid organ transplantation. Int J Radiat Oncol Biol Phys. 1988;15:979-88.

26. Wecker H, Winn HJ, Auchincloss H Jr. CD4+ T cells, without CD8+ or B lymphocytes, can reject xenogenic skin grafts. Xenotransplantation. 1994;1:8-12.

27. Chitilian HV, Laufer TM, Stenger K, Shea S, Auchincloss H Jr. The strength of cell-mediated xenograft rejection in the mouse is due to the CD4+ indirect response. Xenotransplantation. 1998;5:93-8.

28. Yamaoka K, Kim KM, Ishigami T, et al. Cyclosporin A and FK506 block the negative signaling mediated by surface IgM cross-linking in normal human mature B cells. Immunol Lett. 1993;36:203-8.

29. Goldfeld AE, Flemington EK, Boussiotis VA, et al. Transcription of the tumor necrosis factor alpha gene is rapidly induced by antiimmunoglobulin and blocked by cyclosporin A and FK506 in human B cells. Proc Natl Acad Sci U S A. 1992;89:12198-201.

30. Bach FH, Turman MA, Vercellotti GM, Platt JL, Dalmasso AP. Accommodation: a working paradigm for progressing toward clinical discordant xenografting. Transplant Proc. 1991;23:205-7.

\section{Discussion}

Dr Robert E. Michler (Columbus, Ohio). The Loma Linda group is certainly to be congratulated for their excellent work in demonstrating that hearts transplanted in the orthotopic position between the monkey and baboon can survive for over 1 year. Those of us familiar with this model recognize how difficult it is to manage these animals, diagnose rejection, and administer medications. Consistent 1-year orthotopic graft survival is certainly an achievement.
These results, although encouraging, were achieved with an aggressive immunosuppressive regimen that would be difficult to readily apply to the newborn human or young child. It is also difficult to truly compare the effect of the 3 immunosuppressive regimens when the data presented are limited to those recipients who survived beyond the 300-day time point. This situation might be analogous to comparing human immunosuppressive treatment options by looking only at recipients of human allografts who survived beyond an arbitrary time point, say, 5 years. Arguably, there is something special about long-term survivors that cannot be explained by the drug therapy alone.

This animal model is more difficult to manage than the human recipient model. Specifically, diagnosis of rejection requires that the animal be sedated to perform an echocardiogram, drug administration is often problematic, and symptoms cannot be easily ascertained. Because this study was conducted over a 10-year time frame, how certain can we be that the diagnosis and treatment of both rejection and infection were sufficiently uniform to draw such strong conclusions?

The Loma Linda group has continued to scientifically explore transplantation between closely related species, and we must presume that this has been done with a particular clinical objective in mind. It would be interesting to hear comments from the authors on their overall strategy for human clinical application of xenotransplantation. The baboon remains a difficult donor choice for humans from the perspective of availability and potential retroviral transmission to the human recipient. It is likely that imported wild baboons will not be acceptable to the Food and Drug Administration and the Centers for Disease Control and Prevention. Therefore baboons bred in captivity under specific conditions will be required at considerable expense. How do the authors view the likelihood of clinical application and its widespread effect? We recognize and admire the experience of the Loma Linda group in the field of xenotransplantation, as well as in newborn clinical allotransplantation, and therefore they are uniquely qualified to comment and advise us on this issue. Do they believe that the newborn, for example, represents a unique immunologic situation? Moreover, what is their perspective on the pig as a donor animal?

It is possible that public opinion and the concern for transmission of primate endogenous retroviruses will prevent the use of nonhuman primates as donors for human subjects. Nevertheless, the experience gained from studies such as this one reinforces the complexities involved in transplanting organs between species. It is expected that these same limitations will be experienced by investigators attempting to achieve long-term survival of cardiac xenografts between transgenic pigs and nonhuman primates, and there is much that they can learn from the experience of the Loma Linda group.

Every animal model has its limitations, and the need to proceed to the clinical arena with novel therapies must take into consideration the limitations imposed by the particular animal model.

Dr Gundry. If I might be so bold as to respond to these comments for my colleague. Thank you, Dr Michler, for those very pertinent comments, and I think we really agree with most of what you said.

First of all, you brought up that there is a problem looking at only the long-term survivors of all these groups. Obviously, this has been a very long-term project at our institution, extending over 
10 years. And in each case, as we have attempted to refine the immunosuppressive regimen, and we have tried to center on an immunosuppressive regimen that is quite tolerable in a clinical atmosphere. We believe that by looking at the quality of life of the long-term survivors in this report, the regimen $\mathrm{C}$ animals, that is, those receiving TLI with bone marrow infusion coupled with pretransplantation treatment with methotrexate and cyclosporin, seem to have a good quality of life, that is, a very low incidence of rejection and a very low incidence of infection.

We have previously reported on all the surviving groups in previous articles, but it was the purpose of this article to look at what made the long-term survivors, if at all, different among the 3 groups, so that even though we attain significant long-term survival in regimen A animals, for instance, this came at a cost of multiple episodes of infectious disease treatments and problems probably bought on by the splenectomy. Therefore looking at the long-term costs, we again are looking for a clinically applicable model.

Believe it or not, our diagnosis and treatment of both rejection and infection has not changed in our laboratory over the last 10 years. We have always based this on transesophageal echocardiography on the basis of an interpretation of that echocardiogram, as Dr Asano showed you. And the same with the treatment. We have always used an antiviral regimen for the treatment of most of the problems, and I can tell you that most of the problems are of a viral nature. The unique thing about regimen $\mathrm{C}$ is that we did not see that viral infection problem in the regimen $\mathrm{C}$ animals.

We do tend to disagree with Dr Michler about the availability of baboons. Baboons are a ubiquitous species that are viewed as a trash animal in Africa. They reproduce rapidly and easily. The question of retrovirus is well taken. The Centers for Disease Control and Prevention, working with the National Institutes of Health, is looking at Baby Fae's serum, even as we speak, to decide and determine whether there is a presence of any retroviruses in her serum; the results are not available as yet. We are looking forward to those results. Certainly any sort of primate-tohuman transplantation is going to depend on as much information as we can obtain about retroviruses from primates to humans or from baboons to humans.

We do, of course, continue to believe that the newborn is a unique substrate for transplantation, and our now 11-year data continue to bear that out. Newborns are a privileged host.

Last, as you know, we do have experience with unmodified pigs in an orthotopic transplantation model, and we have had survival-consistent survival-up to about 28 days in an orthotopic model with unmodified pigs by using much the same regimen that you have seen here. The problem, we think, with most of the genetic modifications of pigs is that it has only scratched the surface, and with each passing day we are going to see more and more of a vascular rejection rather than the hyperacute rejection. The hyperacute rejection can be easily fixed.

Availability of Journal back issues

As a service to our subscribers, copies of back issues of The Journal of Thoracic and Cardiovascular Surgery for the preceding 5 years are maintained and are available for purchase from Mosby until inventory is depleted. Please write to Mosby, Subscription Customer Service, 6277 Sea Harbor Dr, Orlando, FL 32877, or call $800-654-2452$ or $407-345-4000$ for information on availability of particular issues and prices. 